\title{
NURSES' TRAINING ON DEALING WITH ALCOHOL AND DRUG ABUSE: A QUESTION OF NECESSITY
}

\author{
Sandra Cristina Pillon, Margarita Antonia Villar Luis and Ronaldo Laranjeira
}

PILLON SC et al. - Nurses' training on dealing with alcohol and drug abuse: a question of necessity. Rev. Hosp. Clín. Fac. Med. S. Paulo 58(2):119-124, 2003.

The purpose of this article is to present a brief review on the need for changes in nurses' undergraduate education concerning alcohol and drugs. Specialized literature makes it clear that nurses have difficulties giving care to psychoactive substance users as part of their functions in the various health care sites. This may be associated with a deficiency in formal education. In the face of the social importance concerning these related questions in the scope of research, care, and education, we made an attempt at deepening the study on this theme, which could contribute to changes in practice, care, and undergraduate nursing education.

DESCRIPTORS: Education. Nurses. Alcohol. Drugs.

\section{INTRODUCTION}

The increasing consumption of alcohol and drugs in various age ranges, and among younger persons in particular, currently presents serious health problems to individuals, families, and societies. Although the search for substances that can alter mood, feelings and emotions is as old as the history of humanity itself, in modern society drug abuse occurs in larger proportions than at any other time in history. Stressful life situations, the need for social support, as well as socioeconomic and cultural difficulties, in addition to the strong expansion of profitable trade in connection with psychoactive substances, among other factors, have made individuals more susceptible to addiction to both licit and illicit drugs. Alcohol abuse has become one of the major public health concerns worldwide.

The use of alcohol frequently is found to be a significant health problem, and a high number of economically active adults die or present serious complications. In Brazil, alcoholism reaches $8 \%$ to $10 \%$ of the active adult population. There is a prevalence of alcoholism of $20 \%$ to $25 \%{ }^{1,2}$ among patients seeking medical care, and a significant number of individuals who require other forms of support are estimated to be alcoholic ${ }^{3}$.

Individual, family, and social health damage associated with the abuse of alcohol and drugs has re-

From the School of Nursing - Ribeirão Preto/ SP; Department os Psychiatric Nursing Human Sciences, University of São Paulo and Federal University of São Paulo. Received for publication on April 25, 2002. sulted in reflections on the direction of proposals regarding educational issues concerning that theme in nurses' education, since this issue has not been emphasized in the curricula of undergraduate nursing programs ${ }^{4}$. The demands from people with serious problems related to alcohol abuse require the educational preparation of nurses in order to respond to this population's needs, which stimulates and/or favors changes towards seeking new institutional and social approaches, thus placing nurses in a position where they can face discussions concerning their clinical, educational and research practice. The changing needs of the population and the nature and extent of substance abuse demand that nurses need to be prepared to work with those whose problems are related to drug or alcohol abuse.

Performance of nurses is an essen- 
tial resource in the care of individuals, families, and communities with problems related to the use of psychoactive substances, and in order to carry out their activities, they must be apt in their clinical, cognitive, and relational skills ${ }^{4}$.

In face of the social importance of issues related to alcohol abuse in research, care, and teaching, we seek to disseminate knowledge on that theme, aiming to stimulate a discussion in nursing. This work aims at presenting a theoretical report concerning training in alcohol and drugs for nurses.

\section{THE DEFINITION OF FORMAL TRAINING}

The theme of alcohol and drugs has been addressed by some workers with a focus on the need for qualified nurses. One of the few studies concerning qualification training conducted in Brazil ${ }^{6}$ emphasizes the nurse's caretaker role as an integral part of the interdisciplinary team. It also presents the difficulties, dissatisfaction, and anxiety faced by nurses when they encounter the need to work in this area. Unqualified nurses without previous practical experience perform inefficiently. During the investigation, the author sought to encourage the sensitization as to the necessity of re-thinking about nurses' qualification, in undergraduate and graduate levels, aiming at making them capable to perform in various situations. The conclusion of the work showed that the preparation of these professionals allows them to perform with security and without fear, thus offering them dignity and professional citizenship, in addition to a good quality of life in their jobs. The efficient results obtained by meeting their clients' needs through adequate knowledge ensure an effective contribution for their participation in alcohol and drug programs provided by services aiming at health promotion ${ }^{6}$.

Another study developed with nursing students in Brazilian schools complemented the data obtained by the previously cited research by showing the insufficient educational preparation given to this theme in nursing curricula. It demonstrated that there is not an agreement among schools in terms of the content offered, there was a multiplicity of theoretical and clinical approaches, and there was no minimum standardized number of hours that should be devoted to the curriculum. The study also shows the interest of students in obtaining specific knowledge ${ }^{8}$.

The international literature shows signs of the inconsistent or inadequate educational preparation on this theme, as well emphasizes that this situation can lead to inadequate practice impregnated with prejudice, which is reflected on the care given. All of these studies give an account in favor of offering specific knowledge concerning alcohol and drugs in formal and complementary education by means of training, since they consider this theme as vital in nurses' education ${ }^{9-15}$.

Therefore, it is confirmed that in both national and international specialized literature there is an agreement concerning the inadequate education of nursing professionals, which results in inadequate practice and in the maintenance of prejudice and moral value judgment in the care of alcohol and drug users.

Much has been said about the education of nurses in relation to the theme of alcohol and its consequences. Therefore, in the context of institutionalized education, the subject of continuing education, which is also known as training or updating, arises. In general, emphasis is given to the need to offer a form of educational support to these professionals in their fields of performance and particularly in academic education.
In Brazil, studies indicate that nurses have little interest in research concerning continuing professional education, although the members of the nursing team seek to participate in training sessions offered by institutions as a resource to qualify and update themselves in specific areas of knowledge ${ }^{5}$.

The updating and training nomenclature that is usually used to refer to the measures taken in order to face this problem reflect a restricted vision. These terms suggest a concern about a product, whereas what is desirable is a form of continuing education, a process that can provide the nursing professional with the necessary support for continued learning during the course of professional progress. In other words, a continuing form of education that will permeate the individual's work is needed; this type of education does not have a deadline and is not focused on a finished product, in contrast to the case of mastering of a new technique at a certain moment of life $\mathrm{e}^{16-17}$.

Therefore, nurses' education must be understood as a continual process that includes two phases: first, education during the nursing undergraduate program, which precedes professional practice; and second, the training that can take place at any time during their professional performance.

Training is regarded as an essential condition for work development. This demand lies in the constant changes in nurses' practice resulting from the demands imposed by health needs. Development consists of an educational strategy that aims at following and continually participating in the progress in scientific knowledge, as well as in the accelerated technological development presently faced by societies. Training can also be a way to correct the failures in formal education, since deficiency in teaching is common to all undergraduate programs for health professionals. ${ }^{18}$ 
In a broader sense, nurses' training can be defined as "all the practical activities in which professionals are involved (as performers in the professional practice) and that are structured in order to contribute to the improvement of their performance" 19 .

Two aspects are emphasized for this definition: training with regard to planned or structured activities and the professional development of nurses involved in the training. The latter emphasizes the major reason for the creation of this activity ${ }^{16}$.

In the search for professional improvement, 3 aspects are identified: the development of competence in order to enable professionals to play their specific roles; the development of the human being, which is potentially reflected in professional performance and enriches the nurses' relationship with the patient, family, and the community; and the acquisition of the ability to implement curricular reform. ${ }^{19}$

Significant training in educational practice requires considerable amount of time and results from the systematic development of personnel in the long term. It is an intentional planned process that aims at professional change (behavior, attitudes, beliefs, and values), an activity that has a definite objective and is committed to individual and organizational systems changes. This will be attained through changes in people and their interpersonal relations and not through rules, structures, functions, or the physical environment (although all this can be related to such changes). It is achieved by means of continual development. ${ }^{19}$

\section{STUDIES ON NURSES' TRAINING}

The American Nurses Association ${ }^{20}$ conducted a study with 1,500 nurses specialized in psychiatry and mental health. It showed that only $10 \%$ of the interviewees felt that they were capable of caring for clients with problems related to the use of psychoactive substances, although most of them had contact, during their daily practice, with a significant number of clients who were users or addicted. As to nurses working in centers for addiction treatment, data revealed that they presented low levels of theoretical knowledge and clinical skills as compared with physicians, social workers, and counselors in the program. Based on these results, the Association concluded that the education received by the nurses had been inadequate and that consequently they required specific training.

An evaluation study on nurses' training concerning psychoactive drugs that used an outline of training needs showed that these professionals presented low levels of skills and knowledge in 8 of the 12 areas related to interventions, which pointed out that, without training, nurses are restricted in the performance of their functions concerning prevention, intervention, and treatment activities ${ }^{21}$.

In spite of the increase in social awareness concerning the dangers and outcomes of alcohol abuse, few nurses have received formal education in how to identify patients with problems and how to take adequate measures or to plan effective intervention ${ }^{10,12}$. Basic knowledge on alcohol and its consequences has not been included in nurses' general education, and in ad- dition, this content lacks a consistent direction, such as a minimum space in the curricula of undergraduate nursing programs. Some studies show similarities in this aspect, pointing out that nursing schools offer 4 to 6 hours of classes with themes concerning this subject in their curriculum, which could explain why many nurses have difficulties in working with this population $^{11-15}$. These data are in agreement with the previously cited Brazilian research $^{7}$.

According to a report from the $\mathrm{Ad}$ visory Council on the Misuse of $\operatorname{Drugs}^{22}$, training emphasizing the early identification by nurses of the issues related to the abuse of psychoactive substances is a fundamental step towards the prevention of the aggravation of problems or to the detection of those problems related to substance abuse. Untrained and inadequately prepared professionals may fail to observe important indicators while giving care.

The World Health Organization and the International Nursing Coun$\mathrm{cil}^{23}$ recommend that, among educational themes, nurses should be given formal education concerning the abuse of psychoactive substances, beginning with basic training and formal education, which should be offered to all nursing students and nurses involved in the health area, as shown by the following model:

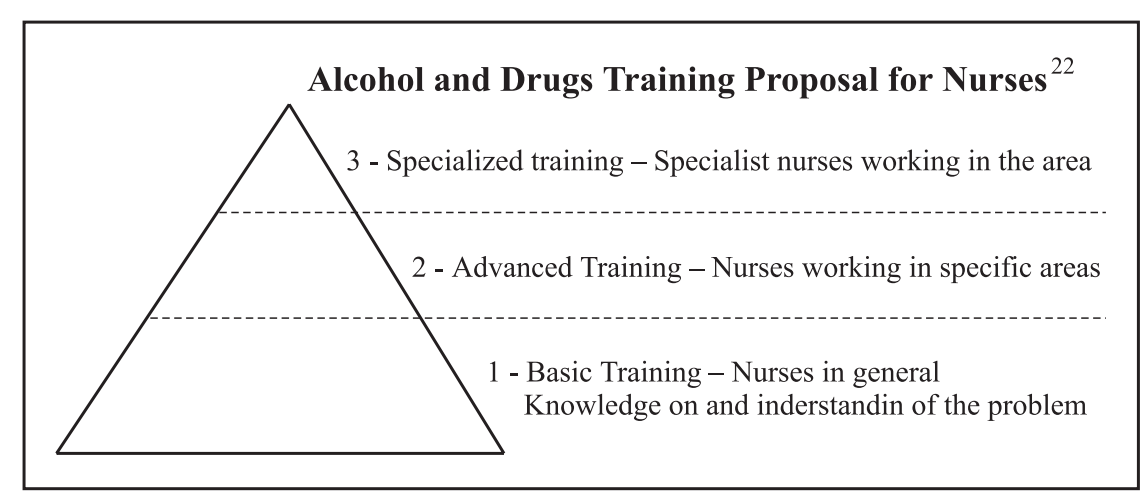

Source: Home Office (1990). 
1- Basic Training - This training involves development of awareness and understanding of the problem, that is, a sensitization to the issue. It should provide information concerning psychoactive substances, the problems related to their abuse, as well as an adequate environment for the exploration of nurses' personal and social attitudes concerning abuse and addiction. This training level can facilitate the recognition of the fact that the problem is associated with the abuse of a substance, thus generating a solid warning response concerning the problem, but without supporting an illusion by professionals that they are capable of solving all the problems. The focus is primarily on the person's figure, in addition to the use of the psychoactive substance. The training can include contents such as the identification of the use of psychoactive substances and where to send the client for support services. In the specific case of nursing, the participants in such a training session could be undergraduate students, general hospital clinical nurses as well as other categories, such as nursing technicians, auxiliaries and aides, health agents, or others in important positions in the community or in a specific population.

2- Advanced Training - In this training, the number of professionals involved is more restricted than in the basic level. Health professionals from specialized services or outpatient clinics with specific needs and characteristics requiring technical skills and specific interventions can participate. Occupational nurses working in companies, a type of place where people with drinking problems are expected to be found, would be included in this category. In some situations, these professionals can be given guidance and supervision by another nurse or specialist professional in the area. In this case, knowledge concerning specialized services for treatment referrals is also necessary. In addition, basic training or sensitization courses should be provided to managers in general, as well as to those working in human resources, thus promoting an integrated work environment that can support employees with problems related to the abuse of psychoactive substances. In situations where the company has an outpatient clinic for health care, the nurse can assume the responsibility of care delivery and follow-up.

3- Specialized training - This training must initiate nurses who are directly involved in the care of patients with problems related to the abuse of psychoactive substances so they can provide adequate care. This level includes a variety of theoretical and practical skills, including types of intervention, motivation techniques for behavioral change concerning the use of psychoactive drugs, knowledge of substance interaction, program development, research, and evaluation of results. Knowledge on the approach by different models, theories that explain the phenomenon of substance abuse, the ideological perspectives in services with treatment programs (for example, total abstinence or damage reduction), existing advantages and limits of treatment modalities, as well as the planning of practical activities for the development of the capacity to perform specific skills that are adequate for the various segments related to the problems are also necessary. All the professionals performing in this area should have access to this training level.

This training model has been proposed by the Advisory Council on the Misuse of Drugs ${ }^{22}$ and has a flexible structure that allows professionals, nurses in this case, to advance in each training level according to their interest and performance.
This study shows that education for nurses working with alcohol and drugs has been inadequate at all formal and informal educational levels. It shows that current nurses' education does not facilitate the development of theoretical knowledge, practical skills, or the necessary attitudes to help psychoactive substance users. Additionally, the study points out the difficulty faced by nurses when giving care to these clients.

As previously mentioned, knowledge of alcohol and the consequences of its abuse has been inconsistently included in the curricula of nursing undergraduate programs, even though offering basic education seems to be one of the requirements for the qualification of nurses in the identification of patients with problems related to the abuse of alcohol and other substances and for the referral to specialized treatment whenever necessary. Nurses need to be prepared to take action, including composing an adequate history concerning the consumption patterns of psychoactive substances implementing health intervention and education strategies for the client; evaluating the problems associated with substance use, identifying harmful use or addiction, and providing health care and support during rehabilitation and recurrence prevention.

Nurses have used their theoretical and practical potential to a small extent in the identification and referral of patients with alcohol-related problems. Data from existing investigations reinforces the need to train nurses on alcohol and drugs, although the acquisition of information concerning the problem does not mean that changes in the professional's attitudes and behavior will occur. Instead, the sensitization of professionals so they can effectively work with substance abusers will result in changes in attitudes and behaviors.

These changes can be strengthened 
conjointly with other undertakings, including changes in educational policies concerning alcohol and drugs in nursing graduate and undergraduate programs regarding the integration of care, teaching, and research, so as to overcome the various needs. It is a long-term investment with various possibilities and strategies.

\section{FINAL CONSIDERATIONS}

The reflections in this paper have significant implications for nursing education, since they indicate a lack or omission in nursing curricula concerning themes related to alcohol and drugs.

National and international studies show that little is known about nurses' attitudes and knowledge with regard to the abuse of alcohol and drugs; therefore, subsequent investigations must address this problem and help with the establishment of pathways that can contribute to improvement in the quality of the nursing care provided to abusers, considering that most of the investigated participants have regarded the issue to be sufficiently relevant to be included in the curricula of undergraduate nursing programs.

Teaching about alcohol and drugs can contribute to nurses' education in a new area of performance, since it is in one of the issues that can be developed to enhance continuing professional education and thus contribute to the increased quality of nursing care.
The responsibility for nurses' education as well as the complexity of the issues related to alcohol and drugs point out the need to be attentive and flexible to new knowledge concerning clinical practice by assuming a greater interaction with theory.

Seeking education on alcohol and drugs is a role that should be played by nurses in the context of their clinical practice, as well as in their teaching and research. It is necessary to invest in the education and training of nurses with a broad view of the phenomena related to the abuse of alcohol and drugs by including political educational, and health issues, and by connecting such knowledge to the social, economic, and cultural transformations of societies.

\section{RESUMO}

PILLON SC e col. - Treinamento em álcool e drogas para enfermeiros: uma questão de necessidade. Rev. Hosp. Clín. Fac. Med. S. Paulo 58(2):119-124, 2003.

Este artigo tem como objetivo apresentar uma breve revisão sobre treinamentos em álcool e drogas buscando estimular reflexões para incentivar mudanças no ensino de graduação em enfermagem. A literatura especializada deixa claro que os enfermeiros tem dificuldades em oferecer cuidados aos usuários de substâncias psicoativas como parte das suas funções nos mais diversos locais de saúde. Este fato pode estar associado a uma deficiência da educação formal. Frente à importância social dessas questões no âmbito da pesquisa, assistência e ensino buscamos aprofundar o conhecimento sobre a temática visando contribuir para sua inserção na prática do profissional.

DESCRITORES: Educação. Enfermeiros. Álcool e Drogas. 


\section{REFERENCES}

1. MASUR J, JORGE MR - Dados relacionados a bebida alcoólica e alcoolismo no Brasil: uma revisão. Rev ABP - APAL 1986; 8(4):157-165

2. MINCIS M - Doença hepática alcoólica: atualização. Rev Hosp São Paulo - EPM 1992; 4(1/4):23-31.

3. LARANJEIRA R - Bases para uma política de tratamento dos problemas relacionados ao álcool e outras drogas no Estado de São Paulo. JBP 1996; 45(4):191-199.

4. SULLIVAN EJ - Nursing care of client with substance abuse. Missouri, Mosby, 1995.

5. KOBAYASHI RM, FRIAS MAE, LEITE MMJ - Caracterização das publicações sobre a educação profissional de enfermagem no Brasil. Rev Esc Enferm USP 2001; 35(1):72-79.

6. FARINAZZO A, BERALDO M - Formação com qualidade: o enfermeiro integrante da equipe interdisciplinar como cuidador do dependente químico. Mundo Saúde 2001; 25(3):285-294.

7. RAMOS LH, PILLON SC, CAVALCANTE MB et al. - O Ensino sobre Dependência Química em cursos de Graduação de Enfermagem no Brasil, 1998. Acta Paul Enferm 2001; 14(3):35-43.

8. ELIASON MJ, GERKEN KC - Attitudes shown by nursing college students, staff, and faculty towards substance abuse. J Subst Mis 1999; 4:55 - 163.

9. CRESPIGNY C - Alcohol and other drug problems in Australia: the urgent need for nurse education. Collegian 1996; 3(3):239 .

10. NAEGLE MA - The need for alcohol abuse - Related Education in Nursing Curricula. Alcohol Health Res World 1994; 18(2):52-55.

11. HOFFMAN A, HEINEMAN ME - Substance abuse education in school of nursing: A national survey. J Nurs Educ 1987; 26:282-287.

12. MURPHY S - The urgency of substance abuse education in schools of nursing. J Nurs Educ 1989; 28(6):247-251.
13. RADKE K, ADAMS B, ANDERSON J - Curriculum blueprints for the future: the process of blending beliefs. Nurse Educ 1991; 16(2):9-13.

14. SEARIGHT HR - Screening for alcohol abuse in primary care: current status and research needs. Drug Alcohol Depend 1992; 30:163-167.

15. RUSH B, BASS M, STEWART E et al. - Detecting, presenting and managing patients' alcohol problems. Can Fam Phys 1994; 40:1557-1566.

16. CELANI MAA - A educação continuada do professor. Rev Ciên Cult 1988; 40(2):158-163.

17. VILAS BOAS MA - Conceitos básicos em educação - Análise e Confronto. Rio de Janeiro, SENAC - DN, 1982.

18. COGAN ML - Temas corrientes en la educación de maestros. Cuad Capacit Docent 1981; 6:1-33.

19. YARGER SJ - Innovation in Education. In: HAROLD EM (Ed) - Encyclopedia of Education Research. New York, The Free Press Division of McMillan Pub, 1982.

20. AMERICAN Nurse' Association - Drug and Alcohol Nursing Association, and National Nurses' Society on Addictions The Care of Clients with Addictions: Dimensions of Nursing Practice. Kansas City, American Nurses Association, Kansas City, 1987.

21. BILT VJ, HALL MN, SHAFFER HJ - An Assessment of substance abuse training needs among nurses (part I): applying an index of training needs. J Subst Mis 1997; 2:150-157.

22. ADVISORY Council on the Misuse of Drugs. Problem drug use: A review of training. London, Her Majesty Stationery Office - HMSO 1990. p.14.

23. WHO-ICN - World Health Organization. International Council of Nurses. Nurses responding to substance abuse. Geneva, 1991. 